\title{
Magnetic Resonance Imaging-Based Radiomics for the Prediction of Progression-Free Survival in Patients with Nasopharyngeal Carcinoma: A Systematic Review and Meta-Analysis
}

\author{
Sangyun Lee, Yangsean Choi *D, Min-Kook Seo, Jinhee Jang, Na-Young Shin, Kook-Jin Ahn and Bum-soo Kim \\ Department of Radiology, Seoul St. Mary's Hospital, College of Medicine, The Catholic University of Korea, \\ Seoul 06591, Korea; 22000472@cmcnu.or.kr (S.L.); 21600406@cmcnu.or.kr (M.-K.S.); znee@catholic.ac.kr (J.J.); \\ nyshin@catholic.ac.kr (N.-Y.S.); ahn-kj@catholic.ac.kr (K.-J.A.); bumrad@catholic.ac.kr (B.-s.K.) \\ * Correspondence: phillip007@catholic.ac.kr; Tel.: +82-2-2258-1442; Fax: +82-2-599-6771
}

Citation: Lee, S.; Choi, Y.; Seo, M.-K.; Jang, J.; Shin, N.-Y.; Ahn, K.-J.; Kim,

B.-s. Magnetic Resonance

Imaging-Based Radiomics for the

Prediction of Progression-Free

Survival in Patients with

Nasopharyngeal Carcinoma: A

Systematic Review and

Meta-Analysis. Cancers 2022, 14, 653.

https://doi.org/10.3390/

cancers14030653

Academic Editor: Gino Marioni

Received: 23 December 2021

Accepted: 26 January 2022

Published: 27 January 2022

Publisher's Note: MDPI stays neutral with regard to jurisdictional claims in published maps and institutional affiliations.

Copyright: (C) 2022 by the authors. Licensee MDPI, Basel, Switzerland. This article is an open access article distributed under the terms and conditions of the Creative Commons Attribution (CC BY) license (https:// creativecommons.org/licenses/by/ $4.0 /)$.
Simple Summary: More than 70\% of patients with nasopharyngeal carcinoma (NPC) present with a locoregionally advanced state. Although the initial staging of NPC is primarily based on TNM staging, there is currently no well-established prognostic marker for NPC. Recently, radiomics has received considerable research attention as a potential prognostic biomarker for NPC. The aim of this systematic review and meta-analysis was to comprehensively evaluate the prognostic value of pretreatment magnetic resonance imaging (MRI)-based radiomics for NPC. The analyzed radiomic models demonstrated modest prognostic values, with a pooled mean estimated Harrell's concordance index ( $\mathrm{C}$ index) of 0.762 . The prognostic models developed using more than eight radiomic features had significantly higher $\mathrm{C}$-indices than those developed using fewer features. Our findings provide evidence that MRI-based radiomics may have a modest prognostic role in the treatment of NPC. However, more consistent study protocols are needed to verify the generalizability of radiomics.

\begin{abstract}
Advanced non-metastatic nasopharyngeal carcinoma (NPC) has variable treatment outcomes. However, there are no prognostic biomarkers for identifying high-risk patients with NPC. The aim of this systematic review and meta-analysis was to comprehensively assess the prognostic value of magnetic resonance imaging (MRI)-based radiomics for untreated NPC. The PubMed-Medline and EMBASE databases were searched for relevant articles published up to 12 August 2021. The Transparent Reporting of a Multivariable Prediction Model for Individual Prognosis or Diagnosis (TRIPOD) checklist was used to determine the qualities of the selected studies. Random-effects modeling was used to calculate the pooled estimates of Harrell's concordance index (C-index) for progression-free survival (PFS). Between-study heterogeneity was evaluated using Higgins' inconsistency index $\left(I^{2}\right)$. Among the studies reported in the 57 articles screened, 10 with 3458 patients were eligible for qualitative and quantitative data syntheses. The mean adherence rate to the TRIPOD checklist was $68.6 \pm 7.1 \%$. The pooled estimate of the C-index was 0.762 (95\% confidence interval, $0.687-0.837)$. Substantial between-study heterogeneity was observed $\left(I^{2}=89.2 \%\right)$. Overall, MRI-based radiomics shows good prognostic performance in predicting the PFS of patients with untreated NPC. However, more consistent and robust study protocols are necessary to validate the prognostic role of radiomics for NPC.
\end{abstract}

Keywords: nasopharyngeal carcinoma; radiomics; survival; meta-analysis

\section{Introduction}

Nasopharyngeal carcinoma (NPC) is an endemic cancer in Southeast Asia and Southern China, with an annual incidence rate of 50-80 patients per 1,000,000 population [1]. However, its annual incidence rate in Europe is relatively low at 4.7 patients per 1,000,000 
population [2]. The standard treatment strategy for NPC involves concurrent chemoradiation therapy (CCRT) with or without adjuvant chemotherapy [3]. The prognosis of patients treated with CCRT is relatively fair, with a five-year overall survival and progression-free survival (PFS) rate of approximately $72 \%$ [4].

Initial cancer staging for NPC is primarily based on TNM staging according to the 8th edition of the American Joint Committee on Cancer guidelines [5]. Although TNM staging is currently the gold standard for the prognostication of patients with NPC, recent advances in quantitative magnetic resonance imaging (MRI) sequences, including diffusion-weighted MRI and apparent diffusion coefficient [6,7], dynamic contrast enhancement MRI [7,8], and amide proton transfer imaging [9], have been demonstrated as additional means for the prognostication of patients with untreated NPC.

Radiomics is the analysis of medical images into high-throughput quantitative data. This field has recently gained significant attention in oncologic radiology research as an illustrative example of personalized precision medicine. The underlying hypothesis is that medical images can reveal important data on tumor phenotypes [10], making radiomics a computational biomarker. One of the benefits of radiomics in medical imaging is its applicability in routinely acquired MRI sequences, such as T2-weighted (T2) or contrast-enhanced T1-weighted (CE-T1) MR images, often yielding thousands of quantifiable imaging features. Zhang et al. investigated the prognostic value of multiparametric MRI-based radiomics for advanced NPC cases [11] and found that MRI-based radiomics provides improved prognostication. The prognostic value of radiomics for untreated NPC has been previously established, further supporting its potential role as a prognostic imaging biomarker [12-14].

Clarifying the evidence on the role of radiomics in the prognostication of NPC will promote better clinical decision-making for precision medicine. Therefore, the purpose of this systematic review and meta-analysis was to evaluate the prognostic value of MRIbased radiomics for NPC. This study indicated that MRI-based radiomics shows good prognostic performance in predicting the progression-free survival (PFS) of patients with untreated NPC.

\section{Methods}

This study was conducted according to the Preferred Reporting Items for Systematic Reviews and Meta-Analyses (PRISMA) guidelines [15]. This protocol is registered with Open Science Framework (OSF) at https:/ / doi.org/10.17605/OSF.IO/7KADY (accessed date: 17 January 2022).

\subsection{Literature Search}

The PubMed-MEDLINE and EMBASE databases were searched for relevant original articles on the use of MRI-based radiomics for predicting the prognosis of patients with untreated NPC until 12 August 2021. The following search terms were used: [(nasopharyngeal) AND (cancer OR carcinoma OR squamous cell carcinoma OR malignancy OR tumor) AND (MRI OR MR OR magnetic resonance imaging) AND (radiomics OR radiomic OR texture) AND (survival OR prognosis)]. Only articles published in English, and those involving human patients were included. The bibliographies of the selected articles were further screened to identify other potentially relevant articles.

\subsection{Inclusion and Exclusion Criteria}

The inclusion criteria were as follows, (1) patients: those with pathologically-confirmed NPC without prior treatment, including neoadjuvant chemotherapy, definitive chemoradiation, or radiation therapy; (2) index test: MRI with provision for pretreatment radiomic analysis of primary NPC; (3) reference standard: standards for PFS as determined through clinical/imaging follow-up; and (4) study design: all observational studies (retrospective or prospective).

The exclusion criteria were as follows, (1) case reports, review articles, editorials, letters, and conference abstracts; (2) insufficient data on patients' survival outcomes; (3) lack of 
data on the radiomic analysis of primary NPC; (4) insufficient details on patient survival data and Harrell's concordance index (C-index); and (5) overlapping patient data. Two reviewers (S.L. and Y.C.) independently selected the appropriate study reports using a standardized form.

\subsection{Data Extraction}

The following data were extracted from the included articles in a standardized format: (a) study characteristics (authors, year of publication, study design, and affiliation); (b) cohort characteristics (number of included patients, including the numbers of the patients in the training and validation cohorts, patients' mean age, sex, cancer stages, and type of treatment received); (c) MRI protocols (MR pulse sequences used, MR Tesla, manufacturer, and name of scanner); (d) characteristics of radiomic analysis (segmentation software, segmentation method, radiomic software, feature selection method, number of selected radiomic features, use of internal or external validation, and type of algorithm); and (e) model performance metrics (types of models built and their $\mathrm{C}$-indices in the training and validation cohorts). Radiomic models were chosen for analysis for studies in which the C-indices of multiple survival models were reported.

\subsection{Quality Assessment Based on the TRIPOD Statement and RQS}

Two reviewers (S.L. and Y.C.) independently extracted the data from the articles and performed a quality assessment in consensus. The studies reported in the included articles were evaluated using the Transparent Reporting of a Multivariable Prediction Model for Individual Prognosis or Diagnosis (TRIPOD) checklist, which consists of 22 main criteria with 35 items [16,17]. The type of predictive model was determined as one of the following: development only (type 1a), development and validation using resampling (type $1 b)$, random split-sample validation (type $2 a$ ), nonrandom split-sample validation (type $2 b$ ), validation using separate data (type 3 ), or validation only (type 4 ). To ensure the robustness of the predictive models, only studies of model type $1 \mathrm{~b}$ or higher were included. Furthermore, studies with less than $50 \%$ adherence rate to the TRIPOD checklist items ( $<18$ out of 35 items) were excluded.

Furthermore, the radiomic characteristics of studies were assessed using the Radiomic Quality Score (RQS). RQS consists of six key domains and measures the robustness of the radiomic methodology by scoring specific points for each category up to a total of 36 points [18]. Scoring of the specific RQS items was based on a previous report [19]. The two reviewers (S.L. and Y.C.) independently evaluated RQS and then in consensus.

\subsection{Definitions of Prognostic Endpoints}

The definitions of PFS, local relapse-free survival, distant metastasis-free survival, disease-free survival, and failure-free survival were interchangeable among studies; thus, we collectively defined them as PFS: the interval between the first day of treatment to the date of disease progression (either locoregional recurrences or distant metastases), death from any cause, or the date of the last follow-up visit.

\subsection{Data Synthesis for Meta-Analysis}

The performances of the radiomics models in predicting PFS, measured using the mean $\mathrm{C}$-indices, were the main outcomes of interest. The $\mathrm{C}$-index measures the prognostic performance of models whose outcomes are time-to-event censored data [20]. Only C-indices calculated from the validation or test datasets were used. For studies in which more than one C-index of radiomic models were reported, the one with the highest C-index was chosen. The $95 \%$ confidence intervals (CI) of the associated C-indices were back-calculated to derive their standard deviations (SD) [21]. C-indices calculated from integrated models (i.e., radiomic + clinical or other models) were not used in the analysis. The inverse variance method was used to calculate weights, whereas pooled estimates with their 95\% CI were calculated using DerSimonian-Laird random-effects modeling. Between-study hetero- 
geneity was assessed using Q tests and the Higgins inconsistency index $\left(I^{2}\right)$, with $I^{2}>50 \%$ suggesting heterogeneity [22]. Subgroup meta-regression analyses were performed according to the total number of patients, segmentation method used, number of radiomic features used, external validation, TRIPOD adherence rate, feature selection method, and radiomic software used. Publication bias was assessed using funnel plots and Egger's test [23]. All statistical analyses were performed using R Statistical Software (version 4.1.0, Vienna, Austria) with 'metafor' and 'meta' packages [24,25].

\section{Results}

\subsection{Literature Search}

A flow diagram of the selection process is depicted in Figure 1. A total of 38 unique articles were screened based on their titles and abstracts. Nine articles, including five conference abstracts, three editorials/errata, and one review, were excluded. The full texts of the remaining 29 articles were then thoroughly reviewed. An additional 12 articles were excluded because the studies reported in them were not conducted using MRI $(n=1)$, not in the field of interest $(n=1)$, were missing survival information $(n=5)$, had partially overlapping cohorts $(n=2)$, or involved the analysis of TRIPOD type 1a predictive models $(n=2)$. Of the two studies with overlapping cohorts, the one with a larger sample size was selected. Finally, 10 studies that met the eligibility criteria were included for data synthesis [11,12,26-33].

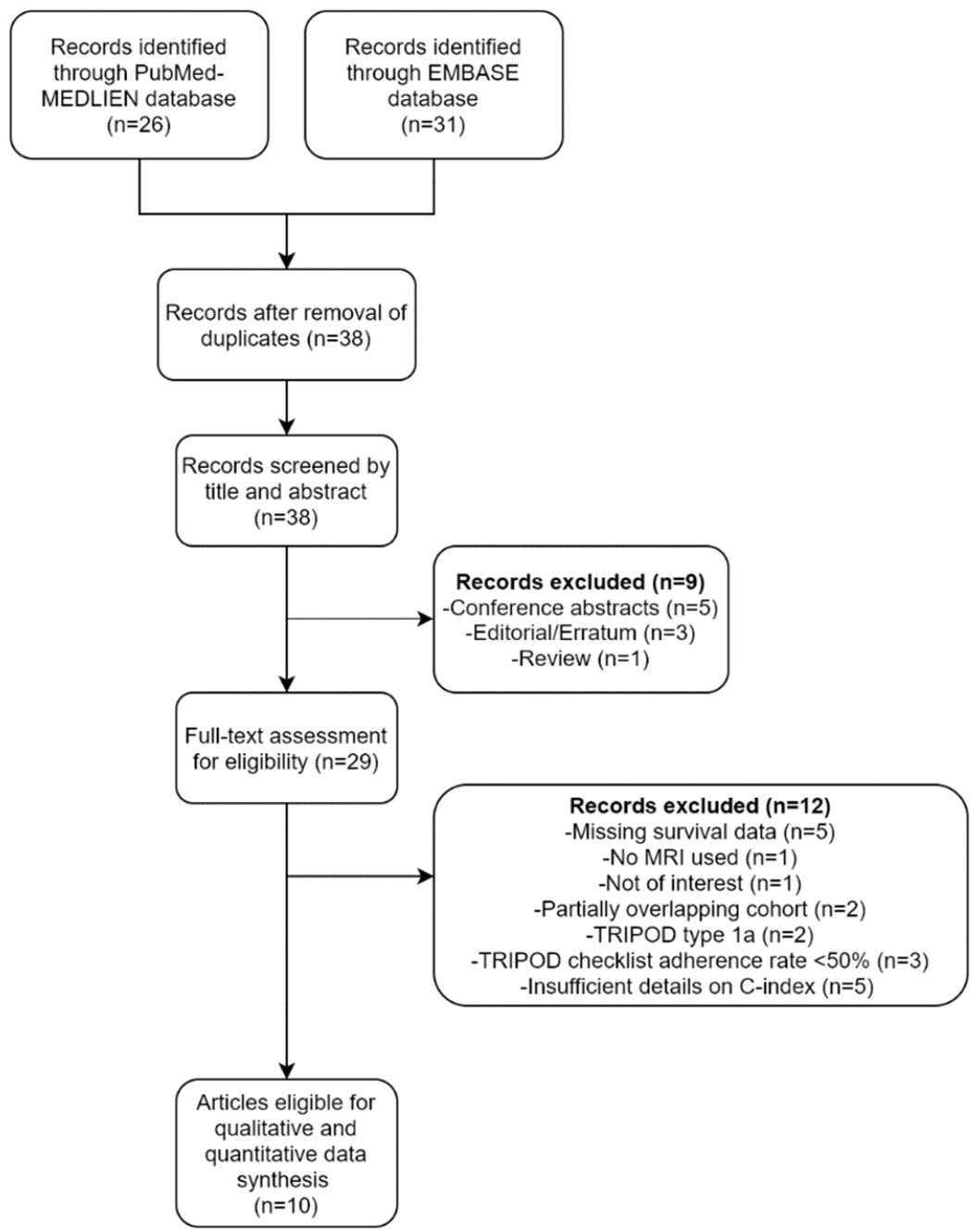

Figure 1. A flow diagram of the study selection process. 


\subsection{Clinical Characteristics and MR Protocols of the Included Studies}

The detailed characteristics of the 10 eligible studies are summarized in Table 1. While one study was a prospective study [31], the others were retrospective studies. Eight studies were conducted in China [11,27-33], one in Italy [26] and one in the Republic of Korea [12]. The type of treatment patients received was not reported in two studies [11,27], whereas the types of treatments received, including a combination of radiation, concurrent chemoradiation, induction chemotherapy, or adjuvant chemotherapy, were reported in the other studies. The 1.5 Tesla and 3.0 Tesla MR scanners were used in six [11,26-29,31] and two studies $[12,33]$, respectively, whereas both the 1.5 and 3.0 Tesla MR scanners were used in two studies [30,32]. T2 and CE-T1 sequences were used in all but two studies, in which only CE-T1 [27] and T2 with non-contrast T1 sequences [26] were used.

\subsection{Radiomic and Image Analyses}

The details of the radiomic and image analyses of the included studies are summarized in Table 2. Regarding the selection of the region of interest, whole tumors were segmented in seven studies [11,12,28-30,32,33], whereas only the largest axial slice was segmented in two studies [26,31]. However, the segmentation method used was not reported in one study [27]. Regarding feature selection methods, the least absolute shrinkage and selection operator (LASSO) was used for feature selection in six studies [11,12,27-29,32], whereas recursive feature elimination [31], stability and correlation-based selection [26], and minimal redundancy maximum relevance with random forest [30], were used in the other studies. Except for one study in which feature selection was not applied [33], the number of radiomic features selected for the prognostic models analyzed in the other studies ranged from two to 20 . Both internal and external validation of the models were performed in only two studies [30,31]. All studies used machine learning algorithms for the radiomic analysis except for two studies that used the deep learning [32] and conventional statistical methods [26].

\subsection{Quality Assessment of the Prediction Models Based on the TRIPOD Statement}

Among the 35 items of the TRIPOD checklist, the mean \pm SD of the reported TRIPOD items was $24 \pm 2.5$. The mean adherence rate and SD of the checklist was $68.6 \pm 7.1 \%$. Most importantly, none of the studies presented their titles as 'developing/validating a model, target population, and the outcome'. Moreover, none of the articles described the handling of data or details of any imputation method. The checklist of the individual TRIPOD items is summarized in Supplementary Table S1.

The basic adherence rate of RQS items is summarized in Table 3. The mean adherence rate was $55 \pm 43 \%$. All studies included validation cohorts and conducted a cut-off analysis (i.e., determining high- and low-risk groups) and discrimination statistics (i.e., reporting C-index with 95\% CI). None of the studies adhered to the RQS items in Domain 5 and 6. The detailed scores of each item are provided in Supplementary Table S2. 
Table 1. Clinical characteristics and magnetic resonance (MR) protocols of the included studies.

\begin{tabular}{|c|c|c|c|c|c|c|c|c|c|c|c|}
\hline $\begin{array}{l}\text { First Author } \\
\text { (Year of } \\
\text { Publication) }\end{array}$ & $\begin{array}{l}\text { Affiliation and } \\
\text { Country }\end{array}$ & Study Period & Study Design & $\begin{array}{l}\text { No. of Patients } \\
\text { (Train- } \\
\text { ing/Validation) }\end{array}$ & $\begin{array}{l}\text { Age [Mean } \pm \\
\text { SD or Median } \\
\quad \text { (Range)] }\end{array}$ & $\begin{array}{c}\text { Proportion of } \\
\text { Male }\end{array}$ & $\begin{array}{c}\text { Overall and } \\
\text { TNM Cancer } \\
\text { Stage }\end{array}$ & $\begin{array}{l}\text { Type of } \\
\text { Treatment } \\
\text { Received }\end{array}$ & $\begin{array}{l}\text { MR } \\
\text { Tesla }\end{array}$ & $\begin{array}{l}\text { MR Pulse } \\
\text { Sequences }\end{array}$ & $\begin{array}{c}\text { MR } \\
\text { Manufacturer } \\
\text { (Scanner } \\
\text { Name) }\end{array}$ \\
\hline Zhang B (2017) & $\begin{array}{c}\text { Guangdong } \\
\text { General Hospi- } \\
\text { tal/Guangdong } \\
\text { Academy of } \\
\text { Medical Sciences, } \\
\text { China }\end{array}$ & $\begin{array}{c}\text { January } \\
\text { 2007-August } \\
2013\end{array}$ & Retrospective & $118(88 / 30)$ & $\begin{array}{c}43(38-51) \\
\text { (training)/ } \\
44(36-51) \\
\text { (validation) }\end{array}$ & $78 \%$ & $\begin{array}{l}\text { Non- } \\
\text { metastatic } \\
\text { III-IVa }\end{array}$ & NR & 1.5 & $\mathrm{~T} 2, \mathrm{CE}-\mathrm{T} 1$ & $\begin{array}{l}\text { GE (Signa } \\
\text { EXCITE HD, } \\
\text { TwinSpeed) }\end{array}$ \\
\hline Zhang L (2019) & $\begin{array}{l}\text { Sun Yat-sen } \\
\text { University Cancer } \\
\text { Center, China }\end{array}$ & $\begin{array}{l}\text { April 2009- } \\
\text { December } \\
2015\end{array}$ & Prospective & $\begin{array}{c}737 \\
{[360 / 120(\text { internal }) /} \\
257(\text { external })]\end{array}$ & $\mathrm{NR}^{1}$ & $75 \%$ & $\begin{array}{l}\text { Non- } \\
\text { metastatic } \\
\text { I-IVa }\end{array}$ & $\begin{array}{c}\text { RT alone or } \\
\text { CCRT } \pm \text { IC } \pm \\
\text { AC }\end{array}$ & 1.5 & $\mathrm{~T} 1, \mathrm{~T} 2, \mathrm{CE}-\mathrm{T} 1$ & $\begin{array}{l}\text { GE (Signa } \\
\text { EXCITE, } \\
\text { SignaHDx), } \\
\text { Siemens } \\
\text { (Espree, } \\
\text { Novus15) }\end{array}$ \\
\hline Zhuo E (2019) & $\begin{array}{c}\text { South China } \\
\text { University of } \\
\text { Technology, China }\end{array}$ & $\begin{array}{c}\text { January } \\
\text { 2010-January } \\
2013\end{array}$ & Retrospective & $658(424 / 234)$ & $\begin{array}{c}45(38-53) \\
\text { (training) } \\
44(37-50) \\
\text { (validation) } \\
\end{array}$ & $73.3 \%$ & $\begin{array}{l}\text { Non- } \\
\text { metastatic } \\
\text { I-IVa }\end{array}$ & Radical IMRT & 3 & $\mathrm{~T} 1, \mathrm{~T} 2, \mathrm{CE}-\mathrm{T} 1$ & $\begin{array}{c}\text { GE (Discovery } \\
\text { MR750) }\end{array}$ \\
\hline Yang K (2019) & $\begin{array}{c}\text { Cancer Center and } \\
\text { State Key } \\
\text { Laboratory of } \\
\text { Biotherapy, West } \\
\text { China Hospital, } \\
\text { Sichuan University, } \\
\text { China }\end{array}$ & $\begin{array}{c}\text { January } \\
\text { 2010-February } \\
2013\end{array}$ & Retrospective & $224(149 / 75)$ & $\begin{array}{c}46 \pm 11 \\
\text { (training) } \\
50 \pm 10 \\
\text { (validation) }\end{array}$ & $70.1 \%$ & III-IVa & $\mathrm{RT} \pm \mathrm{IC} \pm \mathrm{AC}$ & 1.5 & $\mathrm{~T} 2, \mathrm{CE}-\mathrm{T} 1$ & $\begin{array}{l}\text { Siemens } \\
\text { (TrioTrim) }\end{array}$ \\
\hline Shen H (2020) & $\begin{array}{c}\text { Chongqing } \\
\text { University Cancer } \\
\text { Hospital and } \\
\text { Chongqing Cancer } \\
\text { Institute and } \\
\text { Chongqing Cancer } \\
\text { Hospital, China }\end{array}$ & $\begin{array}{l}\text { June } \\
\text { 2013-June } \\
\text { 2017 }\end{array}$ & Retrospective & $327(230 / 97)$ & $\begin{array}{c}52(45-61) \\
\text { (training) } \\
52(45-61) \\
\text { (validation) }\end{array}$ & $72.5 \%$ & $\begin{array}{l}\text { Non- } \\
\text { metastatic } \\
\text { I-IVa }\end{array}$ & $\begin{array}{c}\text { RT alone or } \\
\text { CCRT } \pm \text { IC } \pm \\
\text { AC }\end{array}$ & 1.5 & T2, CE-T1 & $\begin{array}{l}\text { Philips } \\
\text { (Achieva) }\end{array}$ \\
\hline
\end{tabular}


Table 1. Cont.

\begin{tabular}{|c|c|c|c|c|c|c|c|c|c|c|c|}
\hline $\begin{array}{l}\text { First Author } \\
\text { (Year of } \\
\text { Publication) }\end{array}$ & $\begin{array}{l}\text { Affiliation and } \\
\text { Country }\end{array}$ & Study Period & Study Design & $\begin{array}{l}\text { No. of Patients } \\
\text { (Train- } \\
\text { ing/Validation) }\end{array}$ & $\begin{array}{l}\text { Age [Mean } \pm \\
\text { SD or Median } \\
\quad \text { (Range)] }\end{array}$ & $\begin{array}{c}\text { Proportion of } \\
\text { Male }\end{array}$ & $\begin{array}{l}\text { Overall and } \\
\text { TNM Cancer } \\
\text { Stage }\end{array}$ & $\begin{array}{l}\text { Type of } \\
\text { Treatment } \\
\text { Received }\end{array}$ & $\begin{array}{c}\text { MR } \\
\text { Tesla }\end{array}$ & $\begin{array}{l}\text { MR Pulse } \\
\text { Sequences }\end{array}$ & $\begin{array}{c}\text { MR } \\
\text { Manufacturer } \\
\text { (Scanner } \\
\text { Name) }\end{array}$ \\
\hline $\begin{array}{l}\text { Bologna M } \\
\quad(2020)\end{array}$ & $\begin{array}{c}\text { Fondazione IRCCS } \\
\text { Istituto Nazionale } \\
\text { dei Tumori, Italy }\end{array}$ & 2004-2017 & Retrospective & 136 & $48(39-57)$ & $70 \%$ & I-IV & $\begin{array}{l}\text { RT alone or } \\
\text { CCRT } \pm \text { IC }\end{array}$ & 1.5 & $\mathrm{~T} 1, \mathrm{~T} 2$ & $\begin{array}{l}\text { Siemens } \\
\text { (Magnetom } \\
\text { Avanto) }\end{array}$ \\
\hline Zhong L (2020) & $\begin{array}{l}\text { School of Artificial } \\
\text { Intelligence, } \\
\text { University of } \\
\text { Chinese Academy } \\
\text { of Sciences, China }\end{array}$ & $\begin{array}{l}\text { January } \\
\text { 2010-March } \\
2016\end{array}$ & Retrospective & $638(447 / 191)$ & $\begin{array}{c}41(10-69) \\
\text { (training) } \\
41(16-68) \\
\text { (validation) }\end{array}$ & $69.3 \%$ & $\begin{array}{c}\text { Non- } \\
\text { metastaticI-III }\end{array}$ & $\mathrm{IC}+\mathrm{CCRT}$ & $\begin{array}{l}1.0, \\
1.5, \\
3.0\end{array}$ & $\mathrm{~T} 1, \mathrm{~T} 2, \mathrm{CE}-\mathrm{T} 1$ & $\begin{array}{c}\text { Philips } \\
\text { (Achieva, } \\
\text { Panorama } \\
\text { HFO) GE } \\
\text { (Discovery } \\
\text { MR750, } \\
\text { Espree, Signa } \\
\text { EXCITE, Signa } \\
\text { HDx), } \\
\text { Siemens } \\
\text { (TrioTim) }\end{array}$ \\
\hline Zhang F (2020) & $\begin{array}{l}\text { The Cancer Center } \\
\text { of the Fifth } \\
\text { Affiliated Hospital, } \\
\text { Sun Yat-sen } \\
\text { University, China }\end{array}$ & $\begin{array}{c}\text { January 2013- } \\
\text { November } \\
2019\end{array}$ & Retrospective & $\begin{array}{c}236[132 / 44 \text { (internal) } \\
\quad / 44(\text { external)] }\end{array}$ & $\begin{array}{c}48(19-83) \\
\text { (training) } 49 \\
(27-78) \\
\text { (internal test) } \\
44(24-70) \\
\text { (external test) }\end{array}$ & $72.7 \%$ & $\begin{array}{l}\text { Non- } \\
\text { metastaticI- } \\
\text { IVa }\end{array}$ & RT & $1.5,3$ & $\mathrm{~T} 1, \mathrm{~T} 2, \mathrm{CE}-\mathrm{T} 1$ & $\begin{array}{c}\text { Siemens } \\
\text { (Magnetom } \\
\text { Verio, Avanto) }\end{array}$ \\
\hline Kim M (2021) & $\begin{array}{c}\text { Seoul St. Mary's } \\
\text { Hospital, College } \\
\text { of Medicine, The } \\
\text { Catholic } \\
\text { University of } \\
\text { Korea, Republic of } \\
\text { Korea }\end{array}$ & $\begin{array}{c}\text { June } \\
\text { 2006-October } \\
2019\end{array}$ & Retrospective & $81(57 / 24)$ & $53 \pm 13$ & $75.3 \%$ & $\begin{array}{l}\text { Non- } \\
\text { metastaticI- } \\
\text { IVa }\end{array}$ & CCRT & 3 & $\mathrm{~T} 2, \mathrm{CE}-\mathrm{T} 1$ & $\begin{array}{l}\text { Siemens } \\
\text { (Magnetom } \\
\text { Verio)Philips } \\
\text { (Ingenia) }\end{array}$ \\
\hline
\end{tabular}

${ }^{1}$ Reported as $<62$ or $\geq 62$ years old. AC = adjuvant chemotherapy; CCRT = concurrent chemoradiation therapy; CE-T1 = contrast-enhanced T1-weighted image; IC = induction chemotherapy; IMRT = intensity-modulated radiation therapy; NA = not available; NR = not reported; $\mathrm{SD}=$ standard deviation. 
Table 2. Summary of details of radiomic and image analyses.

\begin{tabular}{|c|c|c|c|c|c|c|c|}
\hline $\begin{array}{c}\text { First Author (Year of } \\
\text { Publication) }\end{array}$ & $\begin{array}{l}\text { Segmentation } \\
\text { Software }\end{array}$ & $\begin{array}{l}\text { Segmentation } \\
\text { Method }\end{array}$ & $\begin{array}{c}\text { Radiomic Software } \\
\text { Used }\end{array}$ & Feature Selection Method & $\begin{array}{c}\text { Number of } \\
\text { Radiomic Features } \\
\text { Selected }\end{array}$ & $\begin{array}{l}\text { Validation } \\
\text { Type }\end{array}$ & $\begin{array}{c}\text { Type of Algorithm } \\
\text { Used }\end{array}$ \\
\hline Zhang B (2017) & ITK-SNAP & Whole tumor & MATLAB & LASSO & 8 & I & ML \\
\hline Ming X (2019) & MIM & Not reported & MATLAB & LASSO & 5 & I & ML \\
\hline Zhang L (2019) & RadiAnt & Largest axial slice & MATLAB & $\begin{array}{l}\text { Recursive feature } \\
\text { elimination }\end{array}$ & 11 & I \& E & ML \\
\hline Zhuo E (2019) & Analyze Pro & Whole tumor & MATLAB & None & 4863 & I & ML \\
\hline Yang K (2019) & Raystation & Whole tumor & LIFEx & LASSO & 3 & I & ML \\
\hline Shen H (2020) & $\begin{array}{c}\text { In-house software } \\
\text { developed by Philips }\end{array}$ & Whole tumor & $\begin{array}{c}\text { Philips Radiomics } \\
\text { Tool }\end{array}$ & LASSO & 20 & I & ML \\
\hline Bologna M (2020) & Not reported & Largest axial slice & PyRadiomics & $\begin{array}{l}\text { Stability-based selection, } \\
\text { correlation-based selection }\end{array}$ & 2 & I & Statistical method \\
\hline Zhong L (2020) & ITK-SNAP & Whole tumor & PyRadiomics & LASSO & 3 & I & $\mathrm{DL}$ \\
\hline Zhang F (2020) & ITK-SNAP & Whole tumor & PyRadiomics & $\begin{array}{l}\text { ICC, minimal redundancy } \\
\text { maximum relevance, } \\
\text { random forest }\end{array}$ & 12 & I \& E & ML \\
\hline Kim M (2021) & 3D Slicer & Whole tumor & PyRadiomics & LASSO & 7 & I & ML \\
\hline
\end{tabular}

$\mathrm{DL}$ = deep learning; $\mathrm{E}$ = external validation; $\mathrm{I}$ = internal validation; $\mathrm{LASSO}$ = least absolute shrinkage and selection operator; $\mathrm{ML}=$ machine learning. 
Table 3. Basic adherence rate of the RQS items.

\begin{tabular}{ll}
\hline \multicolumn{1}{c}{ RQS items } & Adherence Rate \\
\hline Domain 1 & \\
Image protocol quality & $90 \%(9)$ \\
Multiple segmentation & $20 \%(2)$ \\
Phantom study on all scanners & $0 \%$ \\
Imaging at multiple time points & $0 \%$ \\
Domain 2 & \\
Feature reduction or adjustment for multiple testing & $90 \%(9)$ \\
Validation & $100 \%(10)$ \\
Domain 3 & \\
Multivariate analysis with non-radiomics features & $90 \%(9)$ \\
Detect and discuss biologic correlates & $60 \%(6)$ \\
Comparison to gold standard & $90 \%(9)$ \\
Potential clinical utility & $70 \%(7)$ \\
Domain 4 & $100 \%(10)$ \\
Cut-off analysis & $100 \%(10)$ \\
Discrimination statistics & $70 \%(7)$ \\
Calibration statistics & \\
Domain 5 & $0 \%$ \\
Prospective study registered in a trial database & $0 \%$ \\
Cost-effective analysis & \\
Open science and data & $0 \%$ \\
\hline
\end{tabular}

\subsection{Pooled Estimate of C-Indices for PFS}

The pooled estimate of C-indices for PFS was 0.76 (95\% CI, 0.69-0.84) (Figure 2). In addition, there was significant heterogeneity among the studies $\left(I^{2}=89.2 \%\right.$; Cochran's Q method, $p<0.001)$. No publication bias was observed upon visual inspection of the funnel plot (Figure 3); the results of Egger's test showed no bias as well $(p=0.73)$.

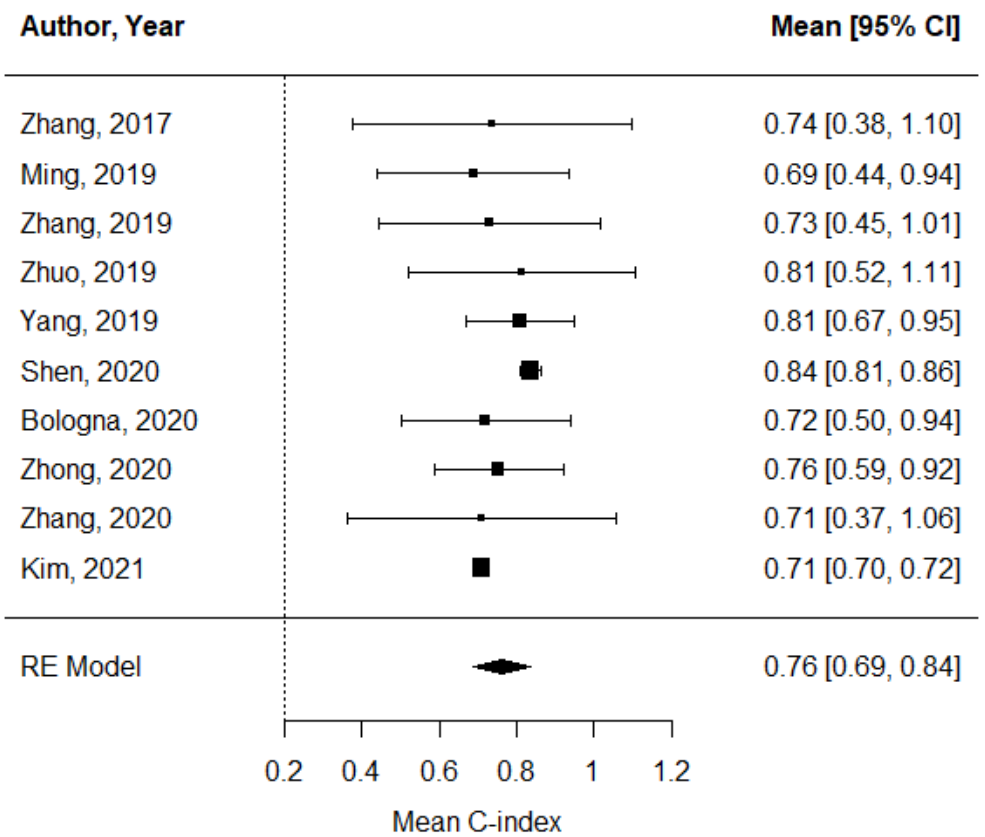

Figure 2. A forest plot of the pooled estimate of C-indices of progression-free survival. 


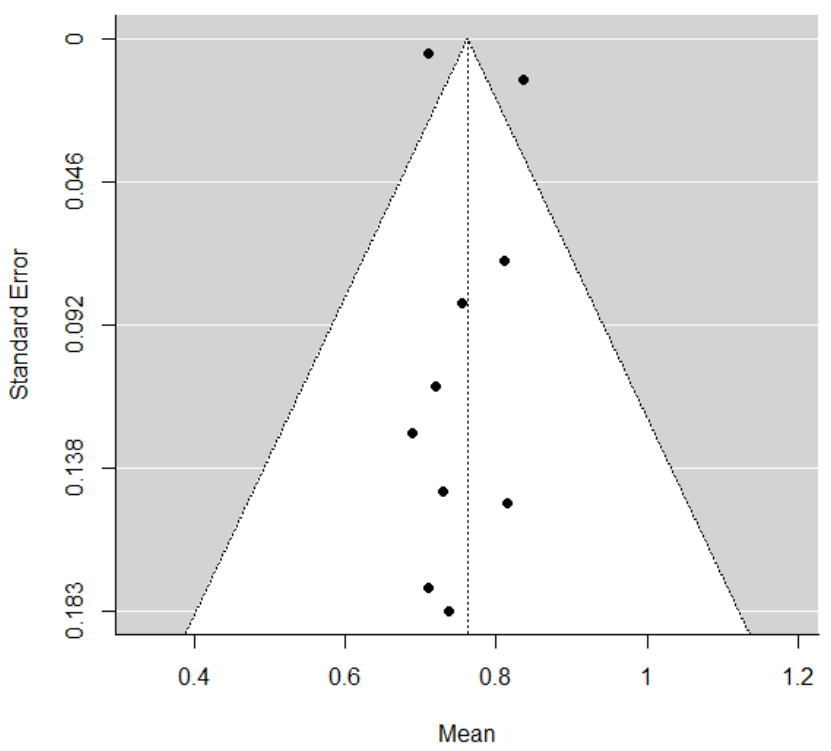

Figure 3. A funnel plot of C-indices.

\subsection{Subgroup Meta-Regression Analyses}

The results of the subgroup meta-regression analysis are shown in Table 4. The number of radiomic features used in the prognostic models and the radiomic software used were found to be the sources of heterogeneity. Models developed using more than eight radiomic features had significantly higher $\mathrm{C}$-indices than those developed with less features $(0.83 \mathrm{vs}$. $0.71, p<0.001$ ). Furthermore, models developed using PyRadiomics for radiomic feature extraction had significantly lower C-indices than those developed using other software ( 0.71 vs. $0.83, p<0.001$ ). Other covariates, including the segmentation method used (whole tumor vs. largest axial slice, $p=0.53$ ), total number of patients ( $>300 \mathrm{vs.} \leq 300, p=0.686$ ), external validation of the prognostic models (yes vs. no, $p=0.542$ ), rate of adherence to the TRIPOD checklist ( $>70 \%$ vs. $\leq 70 \%, p=0.775$ ), and feature selection method (LASSO vs. others, $p=0.975$ ) were not found to be significant sources of heterogeneity. One article [27] did not specify whether the ROI segmentation performed in the reported study was based on the largest axial slice or whole tumor; thus, the study was not included in the subgroup meta-regression analysis of the segmentation method covariate.

Table 4. Subgroup meta-regression analysis of included studies.

\begin{tabular}{|c|c|c|c|}
\hline Covariate & No. of Studies & C-Index $(95 \% \mathrm{CI})$ & $p$-Value ${ }^{1}$ \\
\hline \multicolumn{4}{|l|}{ No. of patients } \\
\hline$>300$ & 5 & $0.76(0.60-0.92)$ & 0.686 \\
\hline$\leq 300$ & 5 & $0.74(0.68-0.78)$ & \\
\hline \multicolumn{4}{|c|}{ Segmentation method $^{2}$} \\
\hline Whole tumor & 7 & $0.75(0.65-0.85)$ & 0.53 \\
\hline Largest axial slice & 2 & $0.72(0.66-0.79)$ & \\
\hline \multicolumn{4}{|c|}{ No. of radiomic features used } \\
\hline$<8$ & 5 & $0.71(0.70-0.73)$ & $<0.001$ \\
\hline$\geq 8$ & 5 & $0.83(0.81-0.86)$ & \\
\hline \multicolumn{4}{|l|}{ External validation } \\
\hline Yes & 2 & $0.72(0.60-0.84)$ & 0.542 \\
\hline No & 8 & $0.74(0.66-0.83)$ & \\
\hline
\end{tabular}


Table 4. Cont.

\begin{tabular}{|c|c|c|c|}
\hline Covariate & No. of Studies & C-Index $(95 \% \mathrm{CI})$ & $p$-Value ${ }^{1}$ \\
\hline \multicolumn{4}{|c|}{ TRIPOD adherence rate } \\
\hline$>70 \%$ & 6 & $0.75(0.63-0.86)$ & 0.775 \\
\hline$\leq 70 \%$ & 4 & $0.73(0.65-0.82)$ & \\
\hline \multicolumn{4}{|c|}{ Feature selection method } \\
\hline LASSO & 6 & $0.74(0.63-0.85)$ & 0.975 \\
\hline Others & 4 & $0.74(0.67-0.82)$ & \\
\hline \multicolumn{4}{|c|}{ Radiomic software } \\
\hline PyRadiomics & 4 & $0.71(0.69-0.73)$ & $<0.001$ \\
\hline Others & 6 & $0.83(0.81-0.85)$ & \\
\hline
\end{tabular}

\section{Discussion}

This systematic review and meta-analysis were conducted to assess the prognostic value of pretreatment MRI-based radiomics for NPC. Based on the pooled estimate of the $\mathrm{C}$-indices of the analyzed models, radiomics revealed an overall modest prognostic value in predicting PFS (mean C-index, 0.76; 95\% CI, 0.69-0.84). However, there was substantial heterogeneity across the studies, which was primarily due to the number of radiomic features included in the prognostic models.

Of the 10 selected studies, the study by Shen et al. reported the highest C-index ( 0.84 ; 95\% CI, 0.64-0.89) [28]. A possible explanation for this might be that except for the study in which feature selection was not performed, the prognostic model in the study by Shen et al. had the largest number of radiomic features $(n=20)$ [33]. This finding is in line with that of our subgroup meta-regression analysis, which showed that the number of radiomic features was a significant factor in determining the performance of the C-index. This is also consistent with the results of a previous study by $\mathrm{Chu}$ et al. which indicated that a larger number of radiomic features is more accurate than a lower number in discriminating pancreatic ductal adenocarcinoma from the normal pancreas [34]. However, it is important to emphasize that radiomic models fitted with a larger number of features are also more susceptible to overfitting, which in turn inevitably impacts the reproducibility in external datasets. In this regard, the two studies that reported C-indices of 0.73 and 0.71 obtained from the external validation cohorts [30,31] may provide higher clinical values than other studies with internal validation cohorts. Of note, the study by Zhang et al. [31] applied the harmonization of MR images to correct for inter-scanner variabilities, which is particularly important for standardizing radiomic features obtained from different MRI scanners.

Interestingly, between-study heterogeneity in the subgroup meta-regression analysis was attributable to the software used for radiomic feature extraction. The models developed using PyRadiomics for radiomic feature extraction demonstrated significantly lower $\mathrm{C}$-indices than those developed using other software. Considering that PyRadiomics is a rigorously tested and maintained software that serves as a reference standard for radiomic analysis [35], it seems counterintuitive that models designed using PyRadiomics showed lower C-indices than those designed using other software. A possible interpretation of this finding is that PyRadiomics-derived radiomic features are more standardized with a relatively smaller number of radiomic features to choose from (around 120 features). However, handcrafted radiomic features acquired using MATLAB are easier to use for additional specifications such as wavelet filter application and log transformations, thus yielding a substantially larger pool of radiomic features. We investigated other possible factors specific to radiomic research that may be responsible for between-study heterogeneity, such as the method of feature reduction or external validation of prognostic models, but none of them yielded meaningful findings. 
Despite the benefits of radiomics in oncologic imaging, its applicability in routine medical imaging without the need for additional advanced time-consuming MRI protocols is limited: a frequent criticism on radiomic research focuses on the lack of reproducibility of radiomic features and generalizability of clinical settings [36]. Among the included studies, many selected radiomic features were highly handcrafted such that none of the features within the same broad category (i.e., gray-level co-occurrence matrix) had any meaningful overlap when they were further subcategorized after the wavelet filter application, which potentially limits the repeatability of the research. One plausible explanation for this finding is the lack of preprocessing (i.e., histogram matching or z-score normalization) of features extracted from MRI sequences in half of the selected studies [11,27-29,33]. Image preprocessing and normalization are especially relevant in the context of MRI scans, where the absolute voxel intensities do not have tissue-specific meanings [37].

It is notable that the mechanism by which specific radiomic features' characteristics may translate into patient prognosis was not reported in several of the studies [28,31,32]. This may lead to limited reproducibility and repeatability of radiomic research. The selected features of importance varied greatly among studies, even among those where the same two sequences (i.e., T2 and T1-CE) were used for feature extraction $[11,12,28,29]$. This suggests that the extraction of radiomic features is highly data-dependent and susceptible to variations in manual segmentations [38].

It is also interesting to note that some of the criteria of the TRIPOD checklist were not met by all studies. For instance, none of the study titles indicated the target population of the study, the outcome of the study, or whether the studies were conducted to develop or validate a model. This is consistent with the findings of a recent study on the quality of reporting radiomics in oncologic studies according to the TRIPOD statement [17]. Among the 77 studies reviewed in that study, only the titles of two studies were in line with the TRIPOD recommendations. Similarly, another study by Heus et al. showed that appropriate titles were the least well-reported items [39]. This may lead to difficulties in identifying published studies on prediction models. As for the RQS assessment, none of the studies met items such as phantom study or multiple imaging acquisition. In retrospective study design, adhering to such items would probably be challenging in clinical settings. Overall, the RQS of the included studies was unsatisfactory with all scores below $50 \%$, which is consistent with other similar systematic reviews based on the RQS [40-42].

This study has some limitations. First, a pooled estimate of overall survival could not be calculated because of the small number of studies with overall survival as the primary endpoint. Second, most of the included studies were conducted in China because NPC is endemic in southern China. Thus, the geographically imbalanced data may limit the generalizability of our findings. Finally, only prognostic models fitted with radiomic features were assessed because clinical factors, and prognostic clinical models, were highly variable across the studies, and thus were not suitable for calculating pooled estimates.

\section{Conclusions}

The findings of the present study suggest that pretreatment MRI-based radiomics has a prognostic value in predicting the PFS of patients with NPC. The subgroup meta-regression analysis showed that the number of radiomic features selected in the prognostic models is significantly associated with C-index performance. However, there was substantial heterogeneity across the studies; thus, more consistent and robust study protocols are necessary in future radiomics research.

Supplementary Materials: The following supporting information can be downloaded at: https: / / www.mdpi.com/article/10.3390/cancers14030653/s1, Table S1: Adherence rate of the TRIPOD items of the included studies; Table S2: Details of radiomic quality score.

Author Contributions: Conceptualization, Y.C.; methodology, Y.C.; formal analysis, Y.C.; investigation, Y.C., M.-K.S. and S.L.; data collection, Y.C. and S.L.; data curation, Y.C. and S.L.; statistical analysis, Y.C.; writing—original draft preparation, Y.C.; writing—review and editing, Y.C.; visu- 
alization, Y.C.; supervision, J.J., N.-Y.S., K.-J.A. and B.-s.K.; project administration, Y.C.; funding acquisition, Y.C. All authors have read and agreed to the published version of the manuscript.

Funding: This research was funded by the Basic Science Research Program through the National Research Foundation of Korea (NRF), funded by the Ministry of Education (2021R1I1A1A01040285).

Conflicts of Interest: The authors declare no conflict of interest.

\section{References}

1. An, X.; Wang, F.H.; Ding, P.R.; Deng, L.; Jiang, W.Q.; Zhang, L.; Shao, J.Y.; Li, Y.H. Plasma Epstein-Barr virus DNA level strongly predicts survival in metastatic/recurrent nasopharyngeal carcinoma treated with palliative chemotherapy. Cancer 2011, 117, 3750-3757. [CrossRef] [PubMed]

2. Tang, L.L.; Chen, W.Q.; Xue, W.Q.; He, Y.Q.; Zheng, R.S.; Zeng, Y.X.; Jia, W.H. Global trends in incidence and mortality of nasopharyngeal carcinoma. Cancer Lett. 2016, 374, 22-30. [CrossRef] [PubMed]

3. Blanchard, P.; Lee, A.; Marguet, S.; Leclercq, J.; Ng, W.T.; Ma, J.; Chan, A.T.; Huang, P.Y.; Benhamou, E.; Zhu, G.; et al. Chemotherapy and radiotherapy in nasopharyngeal carcinoma: An update of the MAC-NPC meta-analysis. Lancet Oncol. 2015, 16, 645-655. [CrossRef]

4. $\quad$ Lin, J.-C.; Jan, J.-S.; Hsu, C.-Y.; Liang, W.-M.; Jiang, R.-S.; Wang, W.-Y. Phase III Study of Concurrent Chemoradiotherapy Versus Radiotherapy Alone for Advanced Nasopharyngeal Carcinoma: Positive Effect on Overall and Progression-Free Survival. J. Clin. Oncol. 2003, 21, 631-637. [CrossRef] [PubMed]

5. Pan, J.J.; Ng, W.T.; Zong, J.F.; Chan, L.L.K.; O'Sullivan, B.; Lin, S.J.; Sze, H.C.K.; Chen, Y.B.; Choi, H.C.W.; Guo, Q.J.; et al. Proposal for the 8th edition of the AJCC/UICC staging system for nasopharyngeal cancer in the era of intensity-modulated radiotherapy. Cancer 2016, 122, 546-558. [CrossRef]

6. Law, B.; King, A.; Bhatia, K.; Ahuja, A.; Kam, M.; Ma, B.; Ai, Q.; Mo, F.; Yuan, J.; Yeung, D. Diffusion-weighted imaging of nasopharyngeal carcinoma: Can pretreatment DWI predict local failure based on long-term outcome? Am. J. Neuroradiol. 2016, 37, 1706-1712. [CrossRef]

7. Zhang, Y.; Liu, X.; Zhang, Y.; Li, W.-F.; Chen, L.; Mao, Y.-P.; Shen, J.-X.; Zhang, F.; Peng, H.; Liu, Q. Prognostic value of the primary lesion apparent diffusion coefficient (ADC) in nasopharyngeal carcinoma: A retrospective study of 541 cases. Sci. Rep. 2015, 5, 12242. [CrossRef]

8. Zheng, D.; Chen, Y.; Liu, X.; Chen, Y.; Xu, L.; Ren, W.; Chen, W.; Chan, Q. Early response to chemoradiotherapy for nasopharyngeal carcinoma treatment: Value of dynamic contrast-enhanced 3.0 T MRI. J. Magn. Reson. Imaging 2015, 41, 1528-1540. [CrossRef]

9. Q Qamar, S.; King, A.D.; Ai, Q.-Y.H.; Mo, F.K.F.; Chen, W.; Poon, D.M.; Tong, M.; Ma, B.B.; Yeung, D.K.-W.; Wang, Y.-X. Pre-treatment amide proton transfer imaging predicts treatment outcome in nasopharyngeal carcinoma. Eur. Radiol. 2020, 30, 6339-6347. [CrossRef]

10. Aerts, H.J.; Grossmann, P.; Tan, Y.; Oxnard, G.R.; Rizvi, N.; Schwartz, L.H.; Zhao, B. Defining a radiomic response phenotype: A pilot study using targeted therapy in NSCLC. Sci. Rep. 2016, 6, 33860. [CrossRef]

11. Zhang, B.; Tian, J.; Dong, D.; Gu, D.; Dong, Y.; Zhang, L.; Lian, Z.; Liu, J.; Luo, X.; Pei, S.; et al. Radiomics Features of Multiparametric MRI as Novel Prognostic Factors in Advanced Nasopharyngeal Carcinoma. Clin. Cancer Res. 2017, 23, 4259-4269. [CrossRef] [PubMed]

12. Kim, M.J.; Choi, Y.; Sung, Y.E.; Lee, Y.S.; Kim, Y.S.; Ahn, K.J.; Kim, M.S. Early risk-assessment of patients with nasopharyngeal carcinoma: The added prognostic value of MR-based radiomics. Transl. Oncol. 2021, 14, 101180. [CrossRef] [PubMed]

13. Zhang, B.; Ouyang, F.; Gu, D.; Dong, Y.; Zhang, L.; Mo, X.; Huang, W.; Zhang, S. Advanced nasopharyngeal carcinoma: Pretreatment prediction of progression based on multi-parametric MRI radiomics. Oncotarget 2017, 8, 72457-72465. [CrossRef] [PubMed]

14. Du, R.; Lee, V.H.; Yuan, H.; Lam, K.O.; Pang, H.H.; Chen, Y.; Lam, E.Y.; Khong, P.L.; Lee, A.W.; Kwong, D.L.; et al. Radiomics model to predict early progression of nonmetastatic nasopharyngeal carcinoma after intensity modulation radiation therapy: A multicenter study. Radiol. Artif. Intell. 2019, 1, e180075. [CrossRef]

15. Moher, D.; Liberati, A.; Tetzlaff, J.; Altman, D.G. Preferred reporting items for systematic reviews and meta-analyses: The PRISMA statement. Ann. Intern. Med. 2009, 151, 264-269. [CrossRef]

16. Collins, G.S.; Reitsma, J.B.; Altman, D.G.; Moons, K.G.M. Transparent Reporting of a Multivariable Prediction Model for Individual Prognosis or Diagnosis (TRIPOD). Circulation 2015, 131, 211-219. [CrossRef]

17. Park, J.E.; Kim, D.; Kim, H.S.; Park, S.Y.; Kim, J.Y.; Cho, S.J.; Shin, J.H.; Kim, J.H. Quality of science and reporting of radiomics in oncologic studies: Room for improvement according to radiomics quality score and TRIPOD statement. Eur. Radiol. 2020, 30, 523-536. [CrossRef]

18. Sanduleanu, S.; Woodruff, H.C.; De Jong, E.E.; Van Timmeren, J.E.; Jochems, A.; Dubois, L.; Lambin, P. Tracking tumor biology with radiomics: A systematic review utilizing a radiomics quality score. Radiother. Oncol. 2018, 127, 349-360. [CrossRef]

19. Lambin, P.; Leijenaar, R.T.; Deist, T.M.; Peerlings, J.; De Jong, E.E.; Van Timmeren, J.; Sanduleanu, S.; Larue, R.T.; Even, A.J.; Jochems, A. Radiomics: The bridge between medical imaging and personalized medicine. Nat. Rev. Clin. Oncol. 2017, 14, 749-762. [CrossRef] 
20. Mayr, A.; Schmid, M. Boosting the concordance index for survival data-A unified framework to derive and evaluate biomarker combinations. PLoS ONE 2014, 9, e84483. [CrossRef]

21. Higgins, J.P.T. ; Cochrane Collaboration. Cochrane Handbook for Systematic Reviews of Interventions, 2nd ed.; Wiley-Blackwell: Hoboken, NJ, USA, 2020.

22. Higgins, J.P.; Thompson, S.G.; Deeks, J.J.; Altman, D.G. Measuring inconsistency in meta-analyses. BMJ 2003, 327, 557-560. [CrossRef] [PubMed]

23. Sterne, J.A.; Egger, M.; Smith, G.D. Investigating and dealing with publication and other biases in meta-analysis. BMJ 2001, 323, 101-105. [CrossRef] [PubMed]

24. Viechtbauer, W. Conducting meta-analyses in R with the metafor package. J. Stat. Softw. 2010, 36, 1-48. [CrossRef]

25. Balduzzi, S.; Rücker, G.; Schwarzer, G. How to perform a meta-analysis with R: A practical tutorial. Evid. Based Ment. Health 2019, 22, 153-160. [CrossRef]

26. Bologna, M.; Corino, V.; Calareso, G.; Tenconi, C.; Alfieri, S.; Iacovelli, N.A.; Cavallo, A.; Cavalieri, S.; Locati, L.; Bossi, P.; et al. Baseline MRI-Radiomics Can Predict Overall Survival in Non-Endemic EBV-Related Nasopharyngeal Carcinoma Patients. Cancers 2020, 12, 2958. [CrossRef] [PubMed]

27. Ming, X.; Oei, R.W.; Zhai, R.; Kong, F.; Du, C.; Hu, C.; Hu, W.; Zhang, Z.; Ying, H.; Wang, J. MRI-based radiomics signature is a quantitative prognostic biomarker for nasopharyngeal carcinoma. Sci. Rep. 2019, 9, 10412. [CrossRef]

28. Shen, H.; Wang, Y.; Liu, D.; Lv, R.; Huang, Y.; Peng, C.; Jiang, S.; Wang, Y.; He, Y.; Lan, X.; et al. Predicting Progression-Free Survival Using MRI-Based Radiomics for Patients With Nonmetastatic Nasopharyngeal Carcinoma. Front. Oncol. 2020, 10, 618. [CrossRef]

29. Yang, K.; Tian, J.; Zhang, B.; Li, M.; Xie, W.; Zou, Y.; Tan, Q.; Liu, L.; Zhu, J.; Shou, A.; et al. A multidimensional nomogram combining overall stage, dose volume histogram parameters and radiomics to predict progression-free survival in patients with locoregionally advanced nasopharyngeal carcinoma. Oral Oncol. 2019, 98, 85-91. [CrossRef]

30. Zhang, F.; Zhong, L.Z.; Zhao, X.; Dong, D.; Yao, J.J.; Wang, S.Y.; Liu, Y.; Zhu, D.; Wang, Y.; Wang, G.J.; et al. A deep-learning-based prognostic nomogram integrating microscopic digital pathology and macroscopic magnetic resonance images in nasopharyngeal carcinoma: A multi-cohort study. Adv. Med. Oncol. 2020, 12, 1758835920971416. [CrossRef]

31. Zhang, L.L.; Huang, M.Y.; Li, Y.; Liang, J.H.; Gao, T.S.; Deng, B.; Yao, J.J.; Lin, L.; Chen, F.P.; Huang, X.D.; et al. Pretreatment MRI radiomics analysis allows for reliable prediction of local recurrence in non-metastatic T4 nasopharyngeal carcinoma. EBioMedicine 2019, 42, 270-280. [CrossRef]

32. Zhong, L.Z.; Fang, X.L.; Dong, D.; Peng, H.; Fang, M.J.; Huang, C.L.; He, B.X.; Lin, L.; Ma, J.; Tang, L.L.; et al. A deep learning MR-based radiomic nomogram may predict survival for nasopharyngeal carcinoma patients with stage T3N1M0. Radiother. Oncol. 2020, 151, 1-9. [CrossRef] [PubMed]

33. Zhuo, E.H.; Zhang, W.J.; Li, H.J.; Zhang, G.Y.; Jing, B.Z.; Zhou, J.; Cui, C.Y.; Chen, M.Y.; Sun, Y.; Liu, L.Z.; et al. Radiomics on multi-modalities MR sequences can subtype patients with non-metastatic nasopharyngeal carcinoma (NPC) into distinct survival subgroups. Eur. Radiol. 2019, 29, 5590-5599. [CrossRef] [PubMed]

34. Chu, L.C.; Park, S.; Kawamoto, S.; Fouladi, D.F.; Shayesteh, S.; Zinreich, E.S.; Graves, J.S.; Horton, K.M.; Hruban, R.H.; Yuille, A.L. Utility of CT radiomics features in differentiation of pancreatic ductal adenocarcinoma from normal pancreatic tissue. Am. J. Roentgenol. 2019, 213, 349-357. [CrossRef]

35. Van Griethuysen, J.J.; Fedorov, A.; Parmar, C.; Hosny, A.; Aucoin, N.; Narayan, V.; Beets-Tan, R.G.; Fillion-Robin, J.-C.; Pieper, S.; Aerts, H.J. Computational radiomics system to decode the radiographic phenotype. Cancer Res. 2017, 77, e104-e107. [CrossRef] [PubMed]

36. Tiwari, P.; Verma, R. The Pursuit of Generalizability to Enable Clinical Translation of Radiomics. Radiol. Artif. Intell. 2020, 3, e200227. [CrossRef] [PubMed]

37. Hoebel, K.V.; Patel, J.B.; Beers, A.L.; Chang, K.; Singh, P.; Brown, J.M.; Pinho, M.C.; Batchelor, T.T.; Gerstner, E.R.; Rosen, B.R. Radiomics Repeatability Pitfalls in a Scan-Rescan MRI Study of Glioblastoma. Radiol. Artif. Intell. 2020, 3, e190199. [CrossRef] [PubMed]

38. Pavic, M.; Bogowicz, M.; Würms, X.; Glatz, S.; Finazzi, T.; Riesterer, O.; Roesch, J.; Rudofsky, L.; Friess, M.; Veit-Haibach, P. Influence of inter-observer delineation variability on radiomics stability in different tumor sites. Acta Oncol. 2018, 57, 1070-1074. [CrossRef] [PubMed]

39. Heus, P.; Damen, J.A.; Pajouheshnia, R.; Scholten, R.J.; Reitsma, J.B.; Collins, G.S.; Altman, D.G.; Moons, K.G.; Hooft, L. Poor reporting of multivariable prediction model studies: Towards a targeted implementation strategy of the TRIPOD statement. BMC Med. 2018, 16, 120. [CrossRef]

40. Spadarella, G.; Calareso, G.; Garanzini, E.; Ugga, L.; Cuocolo, A.; Cuocolo, R. MRI based radiomics in nasopharyngeal cancer: Systematic review and perspectives using radiomic quality score (RQS) assessment. Eur. J. Radiol. 2021, 140, 109744. [CrossRef]

41. Zhong, J.; Hu, Y.; Si, L.; Jia, G.; Xing, Y.; Zhang, H.; Yao, W. A systematic review of radiomics in osteosarcoma: Utilizing radiomics quality score as a tool promoting clinical translation. Eur. Radiol. 2021, 31, 1526-1535. [CrossRef]

42. Stanzione, A.; Gambardella, M.; Cuocolo, R.; Ponsiglione, A.; Romeo, V.; Imbriaco, M. Prostate MRI radiomics: A systematic review and radiomic quality score assessment. Eur. J. Radiol. 2020, 129, 109095. [CrossRef] [PubMed] 